\title{
Altered Respiratory Activity and Respiratory Regulations in Adult Monoamine Oxidase A-Deficient Mice
}

\author{
Henri Burnet, ${ }^{1}$ Michelle Bévengut, ${ }^{1}$ Fouad Chakri,, ${ }^{1}$ Céline Bou-Flores, ${ }^{1}$ Patrice Coulon, ${ }^{2}$ Susana Gaytán, ${ }^{3}$ \\ Rosario Pásaro, ${ }^{3}$ and Gérard Hilaire ${ }^{1}$
}

${ }^{1}$ Centre National de la Recherche Scientifique-Développement et Pathologie du Mouvement, Biologie des Rythmes et du Développement, 13402 Marseille Cedex 20, France, ${ }^{2}$ Centre National de la Recherche Scientifique, Neurocybernetique Cellulaire, 13009 Marseille, France, and ${ }^{3}$ Departamento Fisiología y Biología Animal, Facultad de Biología, Universitad de Sevilla 41012-Sevilla, Spain

The abnormal metabolism of serotonin during the perinatal period alters respiratory network maturation at birth as revealed by comparing the monoamine oxidase A-deficient transgenic (Tg8) with the control (C3H) mice (Bou-Flores et al., 2000). To know whether these alterations occur only transiently or induce persistent respiratory dysfunction during adulthood, we studied the respiratory activity and regulations in adult $\mathrm{C} 3 \mathrm{H}$ and $\mathrm{Tg} 8$ mice. First, plethysmographic and pneumotachographic analyses of breathing patterns revealed weaker tidal volumes and shorter inspiratory durations in Tg8 than in $\mathrm{C} 3 \mathrm{H}$ mice. Second, electrophysiological studies showed that the firing activity of inspiratory medullary neurons and phrenic motoneurons is higher in Tg8 mice and that of the intercostal motoneurons in $\mathrm{C} 3 \mathrm{H}$ mice. Third, histological studies indicated abnormally large cell bodies of Tg8 intercostal but not phrenic motoneurons. Finally, respiratory responses to hypoxia and lung inflation are weaker in Tg8 than in $\mathrm{C} 3 \mathrm{H}$ mice. $\mathrm{DL}-p$-chlorophenyl-alanine treatments applied to Tg8 mice depress the high serotonin level present during adulthood; the treated mice recover normal respiratory responses to both hypoxia and lung inflation, but their breathing parameters are not significantly affected. Therefore in Tg8 mice the high serotonin level occurring during the perinatal period alters respiratory network maturation and produces a permanent respiratory dysfunction, whereas the high serotonin level present in adults alters the respiratory regulatory processes. In conclusion, the metabolism of serotonin plays a crucial role in the maturation of the respiratory network and in both the respiratory activity and the respiratory regulations.

Key words: breathing patterns; inspiratory neuron and motoneuron firing activity; respiratory regulations; morphology of motoneurons; serotonin; maturation; transgenic mice
The nervous control of respiration that has been studied in vivo for several decades, mainly in adult cats, is now being studied in vitro in the neonatal rodent (Hilaire and Duron, 1999) because its respiratory network remains functional in vitro. There is little information regarding the in vivo respiration of the adult mouse (Tankersley et al., 1997, 1999). In addition, the availability of transgenic mice that present interesting mutations affecting the maturation and activity of respiratory network components (Erickson et al., 1996; Jacquin et al., 1996; Bou-Flores et al., 2000) is useful for analyzing the activity and regulations of respiration.

In the $\mathrm{Tg} 8$ strain created from the $\mathrm{C} 3 \mathrm{H} / \mathrm{HeJ}$ strain $(\mathrm{C} 3 \mathrm{H})$ by deletion of the gene encoding monoamine oxidase A (Cases et al., 1995), the serotonin (5-HT) level is 4 - to 10 -fold more than the $\mathrm{C} 3 \mathrm{H}$ level during the perinatal period and remains high $30 \mathrm{~d}$ after birth (twofold) and during adulthood (1.5-fold) (Cases et al., 1995; Lajard et al., 1999). The abnormal metabolism of 5-HT

Received Jan. 29, 2001; revised April 4, 2001; accepted April 12, 2001.

This work was supported by the Centre National de la Recherche Scientifique (CNRS), by a CNRS Action Thématique Incitative sur Programmes et Equique "Virologie" to P.C., and by the "IFR Sciences du Cerveau" and the Ministère de l'Enseignement, de la Recherche et de la Technologie (Programme d'Actions Intégrées franco-espagnol Picasso 00757PC) and a 3 year fellowship to C.B.-F. We thank E. De Mayer and I. Seif (Institut Curie, Orsay, France) for their gift of the transgenic mice, M. Long for correcting the English, and Marie Gardette for helping with the figures.

Correspondence should be addressed to Michelle Bévengut, Centre National de la Recherche Scientifique-Développement et Pathologie du Mouvement, Biologie des Rythmes et du Développement, B.P. 71, 13402 Marseille Cedex 20, France. E-mail: bevengut@dpm.cnrs-mrs.fr.

Copyright (C) 2001 Society for Neuroscience 0270-6474/01/215212-10\$15.00/0 affects the respiratory activity in the $\mathrm{Tg} 8$ neonates by disturbing the maturation of the respiratory network both functionally and morphologically (Bou-Flores et al., 2000). In addition, the modulatory processes that control the respiratory network activity in $\mathrm{C} 3 \mathrm{H}$ neonates are altered in $\mathrm{Tg} 8$ neonates because neither 5-HT nor substance $\mathrm{P}$ modulates their respiratory frequency (Ptak and Hilaire, 1999; Bou-Flores et al., 2000). Whether these abnormalities occur only transiently at birth or persist during adulthood has been an open question. The aims of this in vivo work on the adult mouse were to describe their breathing pattern as well as the firing activity of some respiratory muscles and neurons and to examine whether the abnormal metabolism of 5-HT affects their respiratory regulations.

We show herein that adult $\mathrm{C} 3 \mathrm{H}$ and $\mathrm{Tg} 8$ mice differ in respiratory activity and regulations. Tidal volume, inspiratory duration, and firing levels of inspiratory medullary neurons and spinal motoneurons (Mns) are different in both strains. In addition, inspiratory intercostal motoneurons (IntCMns) present morphological differences. Finally, Tg8 mice are weakly sensitive to both hypoxia and lung inflation, which are the main respiratory regulatory processes originating from the chemosensory pathway of the carotid bodies and the pulmonary stretch-receptor pathway, respectively. The respiratory alterations of the $\operatorname{Tg} 8$ mice may arise either from the maturational disorders occurring during the perinatal period or from the high 5-HT levels still present in the adult. The results of pharmacological treatments performed on Tg8 mice to depress their high level of 5-HT suggest that their 
altered respiratory activity probably arises from abnormal maturation, whereas altered respiratory regulations are more likely to arise from the persistent 5-HT level. Thus in mammals the metabolism of 5-HT plays a crucial role in the maturation of the respiratory network and in both the respiratory activity and regulations.

\section{MATERIALS AND METHODS}

Animals, anesthesia, and drugs

Experiments were performed on mature adult mice belonging to the $\mathrm{C} 3 \mathrm{H} / \mathrm{HeJ}$ strain $(\mathrm{C} 3 \mathrm{H}$, control mice) and its transgenic $\mathrm{Tg} 8$ strain (monoamine oxidase A-deficient mice) (Cases et al., 1995) at least 3 months old and weighing $36 \pm 2 \mathrm{gm}$. In all the invasive experiments, the animals were deeply anesthetized by an intraperitoneal injection of sodium pentobarbitone $(60 \mathrm{mg} / \mathrm{kg})$, tracheotomized, and temperature regulated $\left(37 \pm 1^{\circ} \mathrm{C}\right)$ as reported elsewhere (Burnet and Hilaire, 1999). In the noninvasive experiments, the animals received half doses of sodium pentobarbitone $(30 \mathrm{mg} / \mathrm{kg})$ to suppress all motor activity except respiration. In each of the above conditions, the induction time and the duration of the anesthesia were similar in both strains. In some $\operatorname{Tg} 8$ mice, DL- $p$-chlorophenyl-alanine methyl ester (PCPA) (Sigma, St Louis, MO) diluted in a saline solution $(0.15 \mathrm{M} \mathrm{NaCl})$ was injected at $200 \mathrm{mg} / \mathrm{kg}$ once a day for $4 \mathrm{~d}$ before the experiments.

\section{Measurements and recordings}

Respiratory measurements. As described in detail elsewhere (Burnet and Hilaire, 1999), the respiratory flow was measured via a Fleisch pneumotachograph (type 00000, EMKA Technologies, Paris, France) connected to a differential electromanometer (Validyne CD15, frequency response: DC to $1 \mathrm{kHz}$; Validyne, Northbridge, CA), and the tidal volume $\left(V_{\mathrm{T}}\right)$ was obtained by electrical integration of the respiratory flow signal.

To analyze the respiratory responses to lung inflation, the tracheal cannula was connected to a small solenoid-operated valve (dead space, 40 $\mu \mathrm{l}$; time response, 5-20 msec) (Bioblock Scientific, Illkirch, France) that was electronically driven to block the tracheal flow for $1 \mathrm{sec}$ at the very end of inspiration every 30 respiratory cycles (Burnet and Hilaire, 1999). In some experiments, tracheal occlusions (TOs) of $2 \mathrm{sec}$ were performed during expiration, and a step-by-step motorized syringe was used to inflate the lungs by a defined volume (from 100 to $500 \mu \mathrm{l}$ at a constant speed of $1 \mathrm{ml} / \mathrm{sec}$ ) above the expiratory volume. Several tests were performed on every animal to determine the threshold volume necessary to block the inspiratory on-switch during the $2 \mathrm{sec}$ occlusion period.

The ventilatory responses to hypoxia were studied by the whole-body plethysmography technique, as modified by Bartlett and Tenney (1970) and used repeatedly for studying breathing patterns in mice (Erickson et al., 1996; Jacquin et al., 1996; Tankersley et al., 1997, 1999). The animal chamber $(200 \mathrm{ml})$, equipped with a temperature sensor (Checktemp 1, Hanna Instruments, Lingolsheim, France), was connected to a reference chamber of identical volume. Both chambers were immersed in a thermostated water bath. The pressure difference between the two chambers generated by the inward-outward respiratory flow was measured with a differential pressure transducer connected to a sine-wave carrier demodulator (Validyne CD 15). The signal was amplified, filtered, fed to an analog-to-digital converter (sampling frequency $1 \mathrm{kHz}$ ), and stored on a PC disk via Spike 2 interface and software (Cambridge Electronic Design, Cambridge, UK). Calibrations were performed by injecting $50 \mu \mathrm{l}$ of air into the animal chamber. To study the breathing pattern in control conditions (normoxia), the animal chamber was first flushed for $2 \mathrm{~min}$ with air at $50 \mathrm{ml} / \mathrm{min}$; then the chamber was sealed, and a $20 \mathrm{sec}$ running record was performed. To study the ventilatory response to hypoxia, the animal chamber was flushed for 2 min with a gas mixture (generally nitrogen $90 \%$, oxygen $10 \%$ but occasionally nitrogen $93 \%$, oxygen $7 \%$ ) before the seal was made and the $20 \mathrm{sec}$ recording performed.

Electrophysiological recordings. The global electromyogram of the diaphragm (Dia global EMG) was recorded via two hooks of thin copper wire insulated except at their tips (diameter $100 \mu \mathrm{m}$ ) and implanted through the abdominal muscles by means of the hollow canal of thin needles (diameter $500 \mu \mathrm{m}$ ). The electrical signals were filtered $(0.1-3$ $\mathrm{kHz})$, amplified $\left(5-10 \times 10^{3}\right)$, and integrated through a homemade leaky integrator (time constant $50 \mathrm{msec}$ ).

Pairs of tungsten microelectrodes (impedance $500 \mathrm{k} \Omega$ ) (Frederic Haer, Brunswick, ME) were used to record the unitary activities of the motor units (MUs) of the right costal diaphragm (Dia) and the right inspiratory intercostal muscle of the fifth space (IntC). This latter muscle was chosen because it was easily accessible and it belongs to the rostral group, which has more active inspiratory muscles than those of the caudal group (Monteau and Hilaire, 1991).

To record medullary respiratory neurons, a $1 \mathrm{~cm}$ midline incision was made in the back skin (from the level of the ears downward), and the neck muscles attached to the occipital bone were severed; the skull was then fixed in such a way that the dura between the occipital bone and the first cervical vertebra could be seen and the abdomen was hanging to attenuate the movements of the dorsal medullary surface because of respiration. The dura was then opened, and a tungsten microelectrode (impedance $10 \mathrm{M} \Omega$ ) (Frederic Haer) was inserted in a well defined area of the medulla ( $400-600 \mu \mathrm{m}$ caudal to the obex, $1000-1400 \mu \mathrm{m}$ lateral to the midline, and 1200-1600 $\mu \mathrm{m}$ from the dorsal surface) and lowered with a $1 \mu \mathrm{m}$ step micromanipulator. The signals were filtered $(0.3-10$ $\mathrm{kHz})$, amplified $\left(10 \times 10^{3}\right)$, digitalized $(5-10 \mathrm{kHz})$, stored on a PC disk, and analyzed off-line (Spike2 software). For both MUs and medullary neurons, Spike 2 software routines were used to verify the unitary aspect of the recording and calculate the mean firing frequency during the whole inspiration (meanFtot in Hertz, defined as the number of spikes in the burst divided by the burst duration) and during the three consecutive thirds of the inspiration (meanF1, meanF2, and meanF3 in Hertz, defined as the number of spikes occurring during each third of the inspiration divided by the third of the inspiratory duration). The beginning of inspiration was estimated from the onset of the Dia global EMG (time 0). Spike-triggered-averaging analysis of the ipsilateral Dia global EMG was used to determine whether the medullary neurons excited the phrenic motoneurons (PhrMns) as it does in the cat (Monteau and Hilaire, 1991).

To stimulate the vagus nerve, only the left nerve was dissected and sectioned at neck level, and its central end was mounted on a bipolar silver electrode isolated from the surrounding tissues with Vaseline. A digital stimulator (WPI 830, World Precision Instruments, Sarasota, FL) and an isolation unit (WPI 850) were used to deliver trains of electrical stimuli at weak current intensities $(0.8 \mathrm{msec}$ stimulus duration, 5-20 $\mu \mathrm{A}$, $100 \mathrm{~Hz}$ ) to specifically activate the large vagal afferents (Burnet and Hilaire, 1999).

\section{Neuron morphology and location}

Virus staining. The Challenge Virus Standard fixed strain of rabies virus was used to label the Mns and their serially connected chains of neurons (Astic et al., 1993; Ugolini, 1995). The virus was multiplied in BHK-21 cells (BSR clone) and concentrated through a cushion of $25 \%$ glycerol (Préhaud et al., 1988). The virus stock $\left(2.5 \times 10^{-7} \mathrm{PFU} / \mathrm{ml}\right)$ was kept frozen at $-80^{\circ} \mathrm{C}$ in $20 \mu \mathrm{l}$ aliquots until use. The experiments were performed by vaccinated operators at the appropriate biosafety containment level.

After anesthesia, a $5 \mathrm{~mm}$ incision was made in the skin of the left side at the level of either the 11-12th intercostal space for Dia injections or the 6-7th space for IntC injections. Virus solution $(2 \mu \mathrm{l})$ was injected slowly through a needle inserted in either the left part of the Dia or the left IntC muscles. The wound was then sutured, and the injected animals were kept warm in a confined enclosure maintained in depression. After $4 \mathrm{~d}$ of incubation, the mice were anesthetized deeply and perfused transcardially with $4 \%$ paraformaldehyde in PBS, $\mathrm{pH}$ 7.4. Dissected brains and spinal cords were embedded in a $4 \%$ aqueous solution of Agar (Prolabo, Lyon, France), and serial frontal sections of $70 \mu \mathrm{m}$ thickness were made by means of a vibroslicer (Campden Instruments, Loughborough, UK). The virus was detected by using immunohistochemistry: the mouse monoclonal antibody, specific to the phosphoprotein, a constituent of the rabies nucleocapsid 31G10 (Raux et al., 1997), diluted 1:1000, was used as primary antibody, and a goat anti-mouse IgG (Jackson ImmunoResearch, West Grove, PA) diluted 1:200 was used as secondary antibody. Mouse peroxidase-anti-peroxidase complex (Sigma) diluted 1:500 was used to visualize the infected neurons (Watson and Burrows, 1981). The sections were mounted serially on slides, air dried, dehydrated, and coverslipped with DPX (Sigma). The labeled neurons were viewed under an optic microscope (Axiophot, Zeiss, Le Pecq, France) and photographed.

Fast blue staining. Because the rabies virus labels both the Mns and their synaptically related neurons, Mn morphology was again checked by fast blue (Sigma) staining because this dye does not cross synapses and it retrogradely labeled the cell bodies and their proximal dendrites (Sagot et al., 1998). Each Dia and each IntC of three C3H and four Tg8 mice was 
injected with $2 \mu \mathrm{l}$ of fast blue $(0.5 \%$ in $0.15 \mathrm{M} \mathrm{NaCl})$. After $4 \mathrm{~d}$ the mice were killed and fixed as above. Cervical or thoracic parts of the spinal cord were dissected, embedded in aqueous Agar, and sectioned serially (as above). The sections were mounted serially on slides, air dried, dehydrated, coverslipped, viewed under a Zeiss Axiophot fluorescence microscope, and photographed. The cell bodies of the Mns were drawn at their largest diameters, and their cell body areas were measured with Image software $(\mathrm{NIH})$

Fluoro-Ruby staining. In two $\mathrm{C} 3 \mathrm{H}$ and two $\mathrm{Tg} 8$ anesthetized mice, the anterograde Fluoro-Ruby dye (Molecular Probes, Eugene, OR; 10\% in $0.1 \mathrm{M}$ PBS, pH 7.4) was injected in the medullary area where medullary inspiratory neurons (MINs) were recorded through a $1 \mu \mathrm{m}$ patch-clamp micropipette tip by pressure ejection. Ten days later, the mice were killed, and the brain and cervical parts of the spinal cord were treated as for the fast blue samples except that they were sectioned at $30 \mu \mathrm{m}$. The red-labeled fibers and terminal-like elements (Schmued et al., 1990) were visualized under a Zeiss Axiophot fluorescence microscope.

\section{Statistics}

The data were analyzed as follows with Sigmastat software (SPSS ASC Gmbh, Erkrath, Germany). First, the assumption of normality was checked by the Kolmogorov-Smirnov one-sample test. If the samples were drawn from normally distributed populations, then parametric tests were performed: either a Student's $t$ test for two independent samples (for comparison between the two strains) or a Student's paired $t$ test for paired replicates (for comparison of the same animal under two experimental conditions). Conversely, if the hypothesis of normality was rejected, nonparametric tests were performed, either a Mann-Whitney $U$ test or a Wilcoxon signed-rank test, depending on the experimental paradigms. For histological data, class histograms suggested that the shape of the distribution frequency of cell body areas were different in the two strains; this hypothesis was evaluated by the KolmogorovSmirnov two-sample test. All data were expressed as means \pm SEM. For all tests, statistical significance was taken at $p \leq 0.05$. The parametric tests that were used have been described in detail by Zar (1984), and the nonparametric tests have been described by Siegel and Castellan (1988).

\section{RESULTS}

\section{The breathing pattern is different in $\mathrm{C} 3 \mathrm{H}$ and $\mathrm{Tg} 8$ mice}

The pneumotachographic measurements did not reveal obvious differences in the resting breathing pattern of $19 \mathrm{C} 3 \mathrm{H}$ and $17 \mathrm{Tg} 8$ deeply anesthetized mice (Fig. $1 A$ ). The respiratory activity was stable in both strains, and the durations of the total respiratory cycle $\left(T_{\mathrm{TOT}}\right)$ and the expiratory time $\left(T_{\mathrm{E}}\right)$ were in the same range for $\mathrm{C} 3 \mathrm{H}\left(T_{\mathrm{TOT}}=493 \pm 33 \mathrm{msec}, T_{\mathrm{E}}=333 \pm 30 \mathrm{msec}\right)$ and $\mathrm{Tg} 8$ mice $\left(T_{\text {TOT }}=467 \pm 20 \mathrm{msec}, T_{\mathrm{E}}=336 \pm 20 \mathrm{msec}\right)$, with a respiratory frequency $\sim 120-130$ cycles/min. However, slight but significant differences were observed in inspiratory duration $\left(T_{\mathrm{I}}\right)$ and tidal volume $\left(V_{\mathrm{T}}\right)$ (Fig. $1 B$ ). The mean $T_{\mathrm{I}}$ was significantly shorter by $\sim 30 \mathrm{msec}$ in $\mathrm{Tg} 8\left(T_{\mathrm{I}}=131 \pm 6 \mathrm{msec}\right)$ than in $\mathrm{C} 3 \mathrm{H}$ mice $(160 \pm 10 \mathrm{msec} ; p<0.05)$, and the mean $V_{\mathrm{T}}$ was significantly smaller by $\sim 40 \mu \mathrm{l}$ in $\mathrm{Tg} 8(157 \pm 11 \mu \mathrm{l})$ than in $\mathrm{C} 3 \mathrm{H}$ mice $(197 \pm$ $11 \mu \mathrm{l} ; p<0.02)$.

In the slightly anesthetized $\mathrm{C} 3 \mathrm{H}$ and $\mathrm{Tg} 8$ mice, plethysmographic measurements showed that the respiratory frequency was higher (150-170 cycles/min) than in the deeply anesthetized mice analyzed above. The mean $T_{\mathrm{TOT}}$ and mean $T_{\mathrm{E}}$ were in the same range in $\mathrm{C} 3 \mathrm{H}\left(T_{\text {ТОт }}=357 \pm 29 \mathrm{msec}, T_{\mathrm{E}}=242 \pm 24 \mathrm{msec} ; n=\right.$ $20)$ and $\mathrm{Tg} 8$ mice $\left(T_{\text {TOT }}=391 \pm 59 \mathrm{msec}, T_{\mathrm{E}}=296 \pm 59 \mathrm{msec}\right.$; $n=25$ ), but the mean $T_{\mathrm{I}}$ was again found slightly but significantly shorter in $\mathrm{Tg} 8$ than in $\mathrm{C} 3 \mathrm{H}$ mice $(96 \pm 4 \mathrm{msec}$ vs $114 \pm 9 \mathrm{msec}$; $p<0.05)$. In addition, the mean $V_{\mathrm{T}}$ was smaller by $\sim 60 \mu \mathrm{l}$ in $\operatorname{Tg} 8(156 \pm 16 \mu \mathrm{l} ; n=9)$ than in $\mathrm{C} 3 \mathrm{H}$ mice $(219 \pm 21 \mu \mathrm{l} ; n=8$; $p<0.05)$.

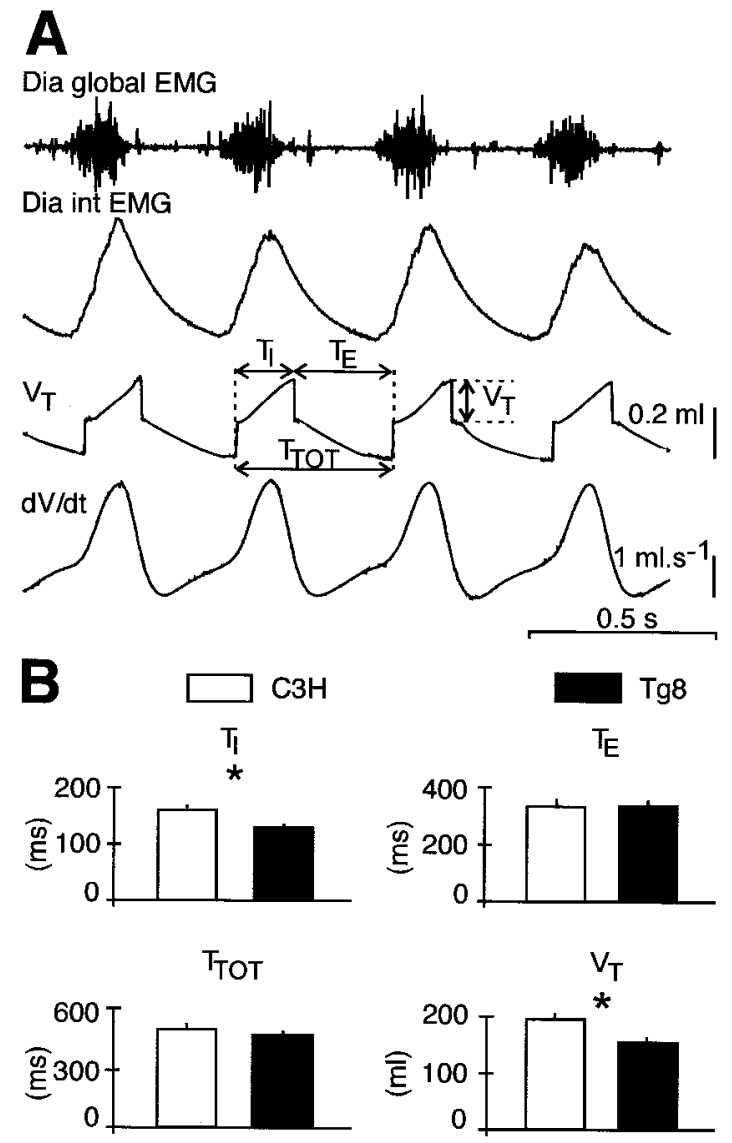

Figure 1. The breathing patterns of $\mathrm{C} 3 \mathrm{H}$ and $\mathrm{Tg} 8$ mice are different. $A$ (top to bottom), Global electromyogram of the diaphragm (Dia global $E M G$ ), integrated Dia global EMG (Dia int $E M G$ ), pneumotachographic recording, tidal volume $\left(V_{T}\right)$, and airflow $(d V / d t)$ in an anesthetized adult $\mathrm{C} 3 \mathrm{H}$ mouse. Breathing parameters are shown: inspiratory duration $\left(T_{I}\right)$, expiratory duration $\left(T_{E}\right)$, total respiratory cycle duration $\left(T_{T O T}\right)$, and $V \mathrm{~T}$. $B$, The histograms give the mean value $( \pm \mathrm{SEM})$ of $T_{\mathrm{I}}, T_{\mathrm{E}}, T_{\mathrm{TOT}}$, and $V_{\mathrm{T}}$ for $19 \mathrm{C} 3 \mathrm{H}$ mice (white bars) and $17 \mathrm{Tg} 8$ mice (black bars). Note that the mean $T_{\mathrm{I}}$ is shorter and the mean $V_{\mathrm{T}}$ smaller in $\mathrm{Tg} 8$ than in $\mathrm{C} 3 \mathrm{H}$ mice $*^{*}$ indicates a statistically significant difference at $p<0.05$ ).

\section{The pattern of discharge of both inspiratory motor units and medullary inspiratory neurons is different in C3H and Tg8 mice \\ Differences in inspiratory motor unit activity}

The unitary activity of 72 motor units from the Dia (DiaMUs) (Fig. $2 A$ ) and 93 MUs from the IntC (IntCMUs) (Fig. 2C) was recorded from $\mathrm{C} 3 \mathrm{H}$ and $\mathrm{Tg} 8$ mice. All MUs were silent during expiration and fired only during inspiration (i.e., the activity in the Dia global EMGs). As shown earlier in cats (Hilaire et al., 1972), inspiratory MUs were not recruited simultaneously at the inspiratory on-switch. Those that started to fire at the very beginning of inspiration were classified as early-recruited MUs (E-MUs); others that were recruited after a delay that was $>10 \%$ of the duration of the Dia global bursts were classified as laterecruited MUs (L-MUs) (Fig. 2A,C).

For the DiaMUs, the mean frequency of discharge during the whole inspiration (meanFtot) of the E-MUs was higher in the Tg8 $(63 \pm 1 \mathrm{~Hz} ; n=18)$ than in the $\mathrm{C} 3 \mathrm{H}$ mice $(56 \pm 2 \mathrm{~Hz} ; n=16$; $p<0.005$ ). In both strains (Fig. $2 B$, left), the discharge frequency increased from the first to the second third of inspiration and decreased slightly during the last third. E-MUs were more active 


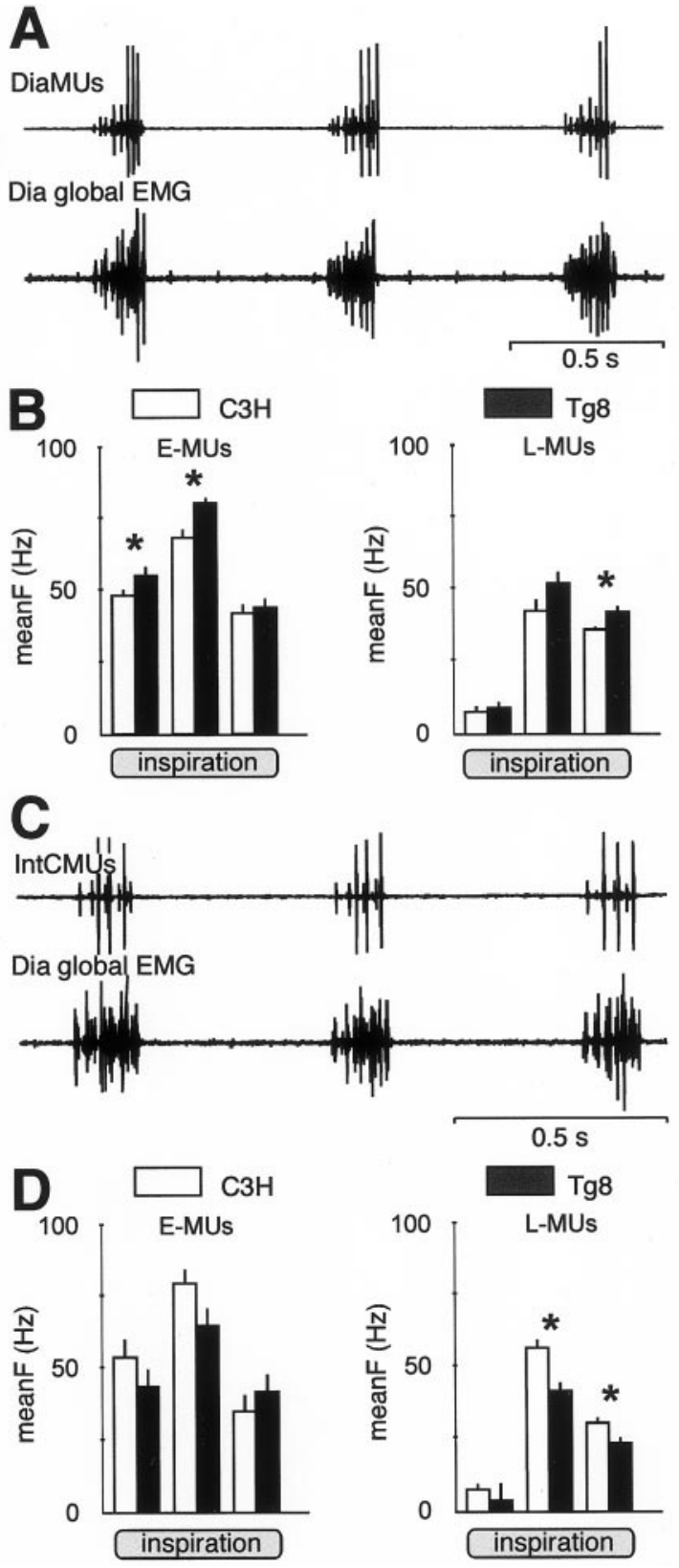

Figure 2. The firing activity of inspiratory motor units is different in $\operatorname{Tg} 8$ and $\mathrm{C} 3 \mathrm{H}$ mice. $A$, Simultaneous EMG recordings from three motor units of the diaphragm (DiaMUs, top trace) and from the Dia global EMG (bottom trace). The three DiaMUs are identified by their spike amplitudes. The small spikes correspond to an early-recruited MU (E-MU); the mid and large spikes correspond to two late-recruited MUs $(L-M U s) . B$, DiaMUs are more active in Tg8 mice (black bars) than in $\mathrm{C} 3 \mathrm{H}$ mice (white bars), as shown by the histograms displaying the mean firing frequency (meanF $\pm \mathrm{SEM}, \mathrm{Hz}$ ) for E-MUs (left histograms) and L-MUs (right histograms) during the first, second, and last third of inspiration (* indicates a statistically significant difference at $p<0.05$ ). In $\mathrm{C} 3 \mathrm{H}$ mice, $\mathrm{E}-\mathrm{MUs}=16$ and L-MUs $=20$; in Tg8 mice, E-MUs $=18$ and L-MUs = 18. $C$, Simultaneous EMG recordings from two intercostal motor units (IntCMUs, top trace) and from the Dia global EMG (bottom trace). D, The histograms of the meanF of the IntCMUs in Tg8 mice (black bars) and in $\mathrm{C} 3 \mathrm{H}$ mice (white bars) show that E-MUs (left histograms) have similar firing activity during the three thirds of inspiration, whereas L-MUs (right histograms) are significantly more active during the last two-thirds of inspiration in the $\mathrm{C} 3 \mathrm{H}$ mice $(*$ indicates a statistically significant difference at $p<0.05$ ). In $\mathrm{C} 3 \mathrm{H}$ mice, E-MUs $=9$ and $\mathrm{L}-\mathrm{MUs}=42$; in $\mathrm{Tg} 8$ mice, $\mathrm{E}-\mathrm{MUs}=6$ and $\mathrm{L}-\mathrm{MUs}=37$. in the $\operatorname{Tg} 8$ mice during the three thirds of inspiration, and the difference was significant during both the first (meanF1 $=55 \pm 2$ $\mathrm{Hz}$ vs $48 \pm 3 \mathrm{~Hz} ; p<0.05)$ and second (meanF $2=80 \pm 2 \mathrm{~Hz}$ vs $68 \pm 3 \mathrm{~Hz} ; p<0.002)$ thirds of inspiration. The L-MUs were also slightly more active during the whole inspiration in the Tg8 (meanFtot $=47 \pm 2 \mathrm{~Hz} ; n=18$ ) than in the $\mathrm{C} 3 \mathrm{H}$ mice (meanFtot $=41 \pm 2 \mathrm{~Hz} ; n=20 ; p=0.057$ ). In both strains (Fig. 2B, right), they fired only few spikes during the first third and increased their discharge frequency during the second third of inspiration. Their firing frequency decreased during the last third of inspiration, but it was significantly higher in $\mathrm{Tg} 8$ than in $\mathrm{C} 3 \mathrm{H}$ mice $($ meanF3 $=42 \pm 2 \mathrm{~Hz}$ vs $36 \pm 1 \mathrm{~Hz} ; p=0.009)$.

As concerns the IntCMUs, the meanFtot of E-MUs was higher in the $\mathrm{C} 3 \mathrm{H}$ (meanFtot $=70 \pm 6 \mathrm{~Hz} ; n=9$ ) than in the Tg8 strain (meanFtot $=57 \pm 4 \mathrm{~Hz} ; n=6$ ) but not significantly different $(p=0.13)$. However, the difference was close to significance during the second third of inspiration (meanF2 $=84 \pm 6 \mathrm{~Hz}$ vs $65 \pm 6 \mathrm{~Hz}$ for $\mathrm{C} 3 \mathrm{H}$ and $\mathrm{Tg} 8$ mice, respectively; $p=0.07$ ) (Fig. $2 D$, left). The meanFtot of L-MUs was also slightly higher but not significantly different $(p=0.11)$ in the $\mathrm{C} 3 \mathrm{H}$ (meanFtot $=50 \pm 2$ $\mathrm{Hz} ; n=37$ ) than in the Tg8 mice (meanFtot $=45 \pm 2 \mathrm{~Hz} ; n=$ 41). They fired at a low rate during the first third of inspiration (Fig. 2D, right) and reached their maximum frequency during the second third of inspiration when their activity was significantly higher in $\mathrm{C} 3 \mathrm{H}$ mice $($ meanF2 $=57 \pm 3 \mathrm{~Hz}$ ) than in $\mathrm{Tg} 8$ ones $($ meanF2 $=42 \pm 3 \mathrm{~Hz} ; p<0.003)$. During the last third of inspiration, they were less active although significantly higher in $\mathrm{C} 3 \mathrm{H}$ than in Tg8 mice $($ meanF3 $=31 \pm 2 \mathrm{~Hz}$ vs $24 \pm 2 \mathrm{~Hz}$ for $\mathrm{C} 3 \mathrm{H}$ and $\mathrm{Tg} 8$ mice, respectively; $p<0.01$ ).

In conclusion, the inspiratory MUs have different firing patterns in $\mathrm{Tg} 8$ and $\mathrm{C} 3 \mathrm{H}$ mice, with a stronger Dia discharge in the $\mathrm{Tg} 8$ strain and a stronger IntC discharge in the $\mathrm{C} 3 \mathrm{H}$ strain.

\section{Differences in medullary inspiratory neuron activity}

The activity of 30 MINs was recorded in a well defined area of the medulla in three $\mathrm{C} 3 \mathrm{H}$ and four Tg8 mice. All of these MINS had the same pattern of discharge (Fig. $3 A$ ); that is, they were silent during mid-expiration, started to fire before the onset of the Dia global EMG, increased their firing activity during inspiration, and fired at a low rate during the beginning of expiration before becoming silent. Before the onset of the Dia discharge (Fig. 3C), MIN firing rate was significantly higher in $\mathrm{C} 3 \mathrm{H}$ than in Tg8 mice $(14 \pm 1 \mathrm{~Hz}$ vs $9 \pm 1 \mathrm{~Hz} ; p<0.05)$. During inspiration, MINs were significantly more active in $\mathrm{Tg} 8$ than in $\mathrm{C} 3 \mathrm{H}$ mice. This was true during the whole inspiration (meanFtot $=65 \pm 5$ $\mathrm{Hz}$ vs $44 \pm 3 \mathrm{~Hz}$, for $18 \mathrm{Tg} 8$ and 12 C3H MINs, respectively; $p<$ $0.05)$ as well as during each of the three thirds of inspiration $($ meanF1 $=51 \pm 6 \mathrm{~Hz}$ vs $39 \pm 4 \mathrm{~Hz}$; meanF2 $=65 \pm 7 \mathrm{~Hz}$ vs $48 \pm$ $6 \mathrm{~Hz}$; and meanF3 $=70 \pm 7 \mathrm{~Hz}$ vs $45 \pm 6 \mathrm{~Hz}$ ). At the transition between inspiration and expiration, MINs decreased their activity $(12 \pm 2 \mathrm{~Hz}$ vs $15 \pm 3 \mathrm{~Hz}$ for $\mathrm{C} 3 \mathrm{H}$ and $\mathrm{Tg} 8$ mice, respectively; NS) and then returned to silence.

Electrophysiological and histological studies suggest that the recorded MINs may be the central drivers of the PhrMns. For four recorded MINs (three in $\mathrm{C} 3 \mathrm{H}$ and one in $\mathrm{Tg} 8$ mice), the recording sessions were long enough to allow a spike-triggeredaveraging analysis of the ipsilateral Dia global EMG by every spike of the MINs $\left(5-10 \times 10^{3}\right.$ spikes). As shown in Figure $3 B$, the Dia global activity was significantly increased $5 \mathrm{msec}$ after the occurrences of the medullary spikes (time 0 ), suggesting that the recorded MINs excited the PhrMns through a paucisynaptic pathway. In four $\mathrm{C} 3 \mathrm{H}$ and four $\mathrm{Tg} 8$ mice, the rabies virus injected 

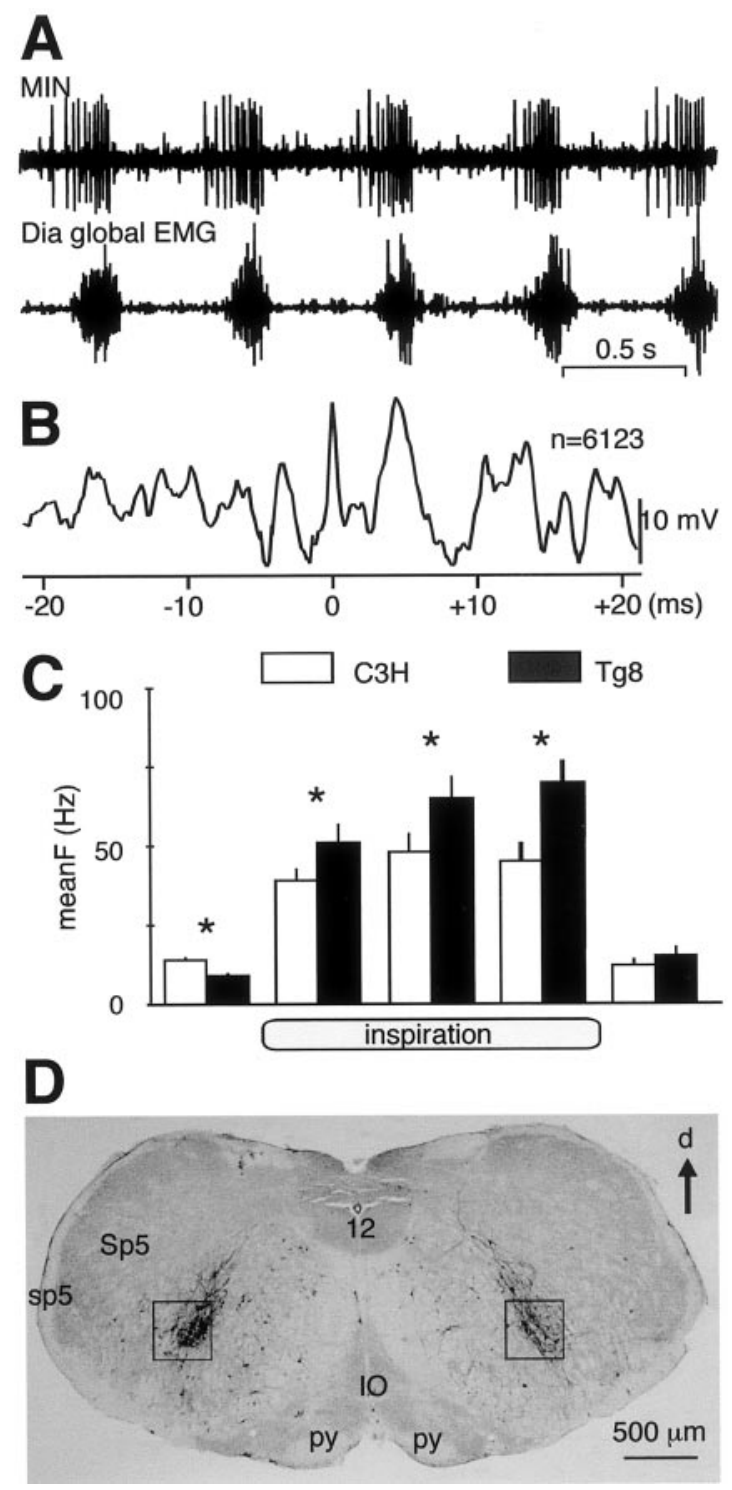

Figure 3. The medullary inspiratory neurons are more active in $\operatorname{Tg} 8$ than in $\mathrm{C} 3 \mathrm{H}$ mice. $A$, Simultaneous recordings from a MIN discharge (top trace) and from the ipsilateral Dia global EMG (bottom trace) in a $\mathrm{C} 3 \mathrm{H}$ mouse. $B$, Spike-triggered-averaging analysis of the Dia global EMG from spikes $(n=6123)$ occurring in the recorded MIN in $A$ shows that the Dia activity increases $5 \mathrm{msec}$ after the occurrences of MIN spikes. $C$, On the basis of recordings from 12 MINs in C3H mice (white bars) and 19 MINs in Tg8 mice (black bars), the histograms show the mean firing frequency (meanF $\pm \mathrm{SEM}, \mathrm{Hz}$ ) of these neurons during respiration. MINs start to fire before inspiration, increase their firing activity during the three thirds of inspiration, and fire at a low rate during the beginning of expiration before becoming silent (* indicates a statistically significant difference at $p<0.05)$. $D$, Four days after the rabies virus has been injected into the left part of the Dia, labeled neurons were found in the medullary areas in which MINs have been recorded (black squares). $d$, Dorsal; $I O$, inferior olive; $s p 5$, spinal trigeminal tract; $S p 5$, spinal trigeminal nucleus; $p y$, pyramidal tract; 12 , hypoglossal nucleus.

in the Dia labeled the PhrMns and their synaptically related neurons. Four days after the injections, numerous infected neurons were found within the area in which MINs were recorded in both strains (Fig. 3D). In two $\mathrm{C} 3 \mathrm{H}$ and two Tg8 mice, FluoroRuby was applied in the MIN area. Ten days later, numerous fibers were stained in the medulla and the ventral horn of the cervical cord (data not shown). Concerning the general pattern of
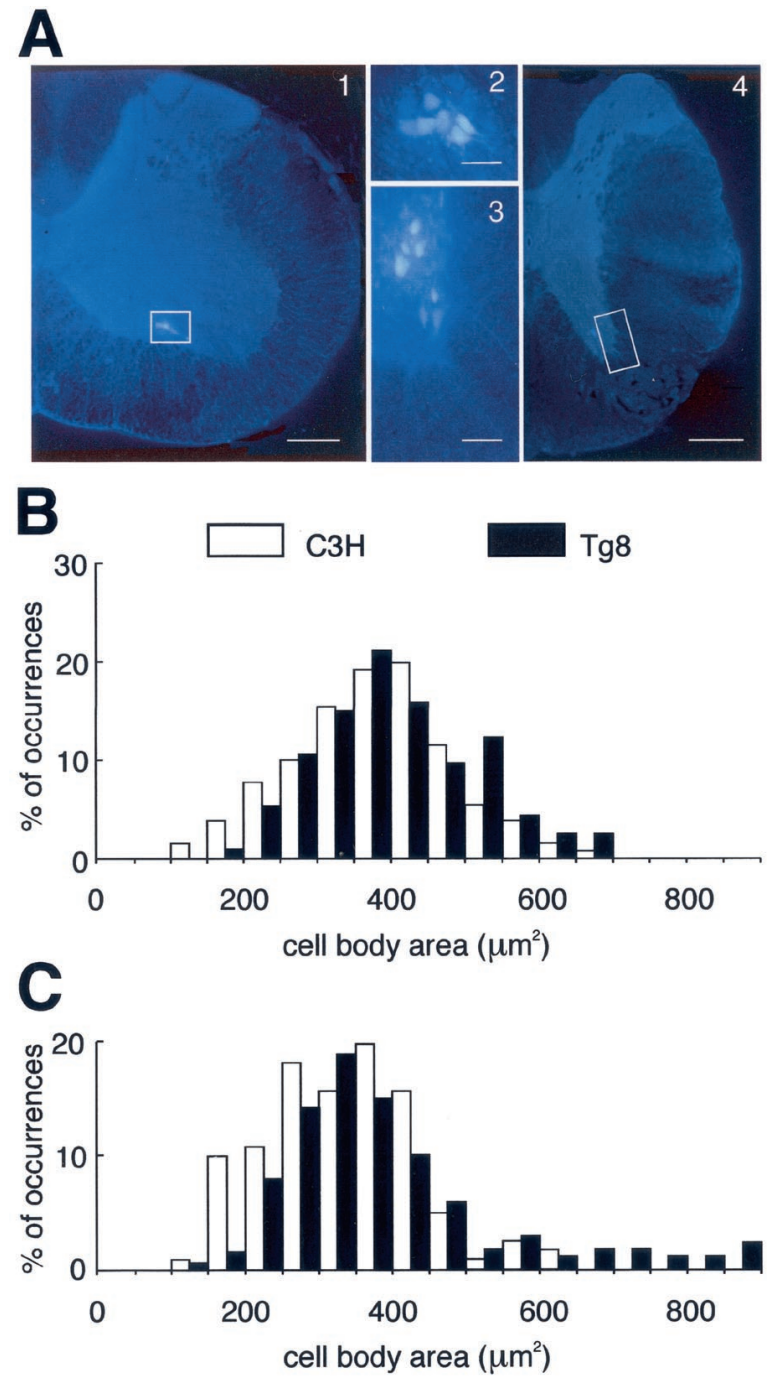

Figure 4. Fast blue staining of inspiratory motoneurons in $\mathrm{Tg} 8$ and $\mathrm{C} 3 \mathrm{H}$ mice. $A$, The phrenic (2) and inspiratory intercostal (3) motoneurons stained with fast blue are located in the cervical (1) and thoracic (4) ventral horns, respectively, of the spinal cord (white boxes). Scale bars: 1 , 4, $200 \mu \mathrm{m} ; 2,3,50 \mu \mathrm{m}$. B, C, The histograms display the percentage of occurrences (\% of occurrences) as a function of the cell body area (in square micrometers) for the phrenic motoneurons $(B)$ and for the inspiratory intercostal motoneurons $(C)$ in three $\mathrm{C} 3 \mathrm{H}$ mice (white bars) and four Tg8 mice (black bars). The histogram distributions are similar in $B$ but different in $C$, in which more frequent small cell body areas $\left(<200 \mu \mathrm{m}^{2}\right)$ are found in $\mathrm{C} 3 \mathrm{H}$ mice and large cell body areas $\left(>500 \mu \mathrm{m}^{2}\right)$ are found in $\operatorname{Tg} 8$ mice.

efferent bulbospinal projections, no difference was found between the two strains. In both cases, the fiber axonal bundles were predominantly ipsilateral, one projecting toward the nucleus of the tractus solitarius in the dorsomedial medulla and the other toward the spinal cord. At cervical level, the efferent fibers presented numerous collaterals toward the PhrMns. Therefore, it is likely that the MINs belong to a neuron pathway synaptically related to the PhrMns. If most of the recorded MINs were PhrMn central drivers, their high firing rate in Tg8 mice may explain why DiaMUs present a high firing rate during inspiration.

\section{Morphology of phrenic and intercostal motoneurons in C3H and Tg8 mice}

The rabies virus was injected into the Dia and IntC muscles of four $\mathrm{C} 3 \mathrm{H}$ and four $\mathrm{Tg} 8$ mice to label their Mns. Measurements of 


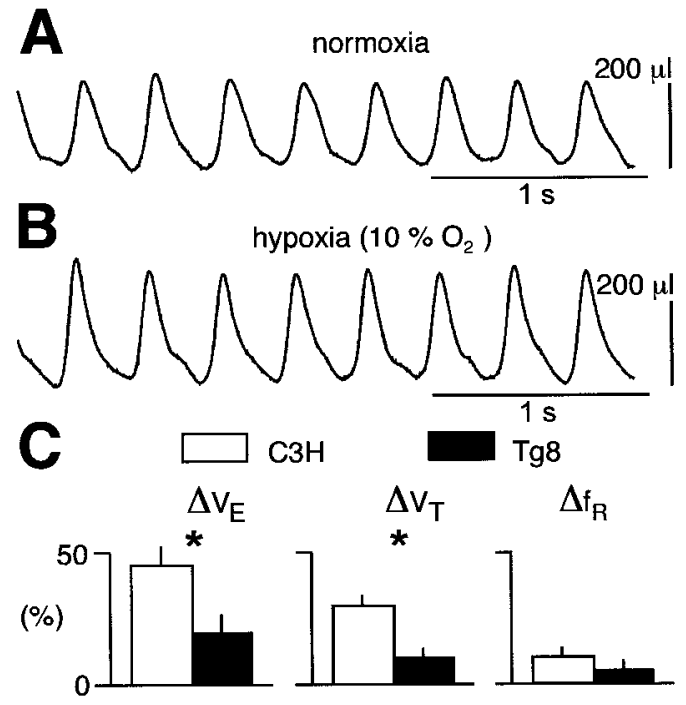

Figure 5. Tg8 mice are less sensitive to mild hypoxia than $\mathrm{C} 3 \mathrm{H}$ mice. $A$, $B$, Plethysmographic recordings of respiration from a $\mathrm{C} 3 \mathrm{H}$ mouse under normoxic $\left(A, 21 \% \mathrm{O}_{2}\right)$ and hypoxic $\left(B, 10 \% \mathrm{O}_{2}\right)$ conditions. $C$, The histograms show the mean variation $( \pm$ SEM) of minute ventilation $\left(\Delta V_{\mathrm{E}}\right)$, tidal volume $\left(\Delta V_{\mathrm{T}}\right)$, and respiratory frequency $\left(\Delta f_{\mathrm{R}}\right)$ elicited by hypoxia in $20 \mathrm{C} 3 \mathrm{H}$ mice (white bars) and $24 \mathrm{Tg} 8$ mice (black bars), expressed as percentage [(\%)] of values obtained during normoxia (* indicates a statistically significant difference at $p<0.05$ ).

the cell body areas in frontal sections of the spinal cord suggest that PhrMns are not different in size in the two strains, whereas IntCMns are larger in $\mathrm{Tg} 8$ than in $\mathrm{C} 3 \mathrm{H}$ mice. Because the rabies virus infects both the Mns and their related interneurons, injections of fast blue dye, which does not migrate transynaptically, were used in these muscles to label only the Mns. For PhrMns (Fig. 4A1, 2), the distribution curves of the measured areas (Fig. $4 B$ ) were not different $(p=0.228)$, and comparison of the two medians did not reveal a statistical difference in their cell body areas (median \pm semi-interquartile range: $384 \pm 78 \mu \mathrm{m}^{2}, n=114$ vs $382 \pm 70 \mu \mathrm{m}^{2}, n=131$ for four $\mathrm{Tg} 8$ and three $\mathrm{C} 3 \mathrm{H}$ mice, respectively; $p=0.072$ ). For IntCMns (Fig. $4 A 3,4)$, the $\mathrm{C} 3 \mathrm{H}$ and Tg8 distribution curves (Fig. $4 C)$ were different $(p=0.016)$, and comparison of the median values therefore had no meaning. However, the frequency of occurrences of small $\left(<200 \mu \mathrm{m}^{2}\right)$ and large $\left(>500 \mu \mathrm{m}^{2}\right)$ cell body areas was significantly different in the two strains ( $\chi^{2}$ test; $\left.p<0.001\right)$, with large IntCMns more frequent in $\mathrm{Tg} 8$ mice and small IntCMns more frequent in $\mathrm{C} 3 \mathrm{H}$ mice.

Therefore, if a large cell body results in a low excitability of the Mn (Henneman et al., 1965a,b; Somjen et al., 1965), the Tg8 IntCMns will display a lower excitability than those of the $\mathrm{C} 3 \mathrm{H}$ mice, and indeed, although the higher firing rate of MINs in Tg8 mice induces a difference of firing activity between the $\mathrm{C} 3 \mathrm{H}$ and Tg8 PhrMns, which have similar cell body sizes, we see that for the IntCMns, the higher firing rate of MINs in Tg8 mice is not able to compensate for the lower excitability of their Mn pool, which results from the presence of large-sized Mns.

\section{Respiratory regulations are different in $\mathrm{C} 3 \mathrm{H}$ and Tg8 mice}

Respiration is regulated mainly by two factors: the oxygen level of the air inhaled and the level of inflation of the lungs. Both of these regulations are altered in adult Tg8 mice.

\section{Respiratory responses to hypoxia}

The breathing patterns under normoxia (Fig. 5A) and mild hypoxia $\left(10 \% \mathrm{O}_{2}\right)$ (Fig. $5 B$ ) were compared in $17 \mathrm{C} 3 \mathrm{H}$ and $19 \mathrm{Tg} 8$ mice by using plethysmography. In the $\mathrm{C} 3 \mathrm{H}$ mice (Fig. $5 \mathrm{C}$, white bars), mild hypoxia induced a large increase in minute ventilation $\left(\Delta V_{\mathrm{E}}=47 \pm 14 \%\right.$ of normoxic condition; $\left.p<0.0001\right)$ mainly because of an increase in $V_{\mathrm{T}}\left(\Delta V_{\mathrm{T}}=31 \pm 7 \% ; p<0.01\right)$, although the respiratory frequency also increased $\left(\Delta f_{\mathrm{R}}=11 \pm 5 \% ; p<\right.$ $0.05)$. In the Tg8 mice (Fig. 5C, black bars), mild hypoxia induced an increase in minute ventilation $\left(\Delta V_{\mathrm{E}}=18 \pm 7 \%\right.$ of normoxic condition; $p<0.05)$ caused by an increase in $V_{\mathrm{T}}\left(\Delta V_{\mathrm{T}}=+11 \pm\right.$ $4 \% ; p<0.05)$, whereas the respiratory frequency remained unchanged $\left(\Delta f_{\mathrm{R}}=+5 \pm 4 \%\right.$; NS). Furthermore, the respiratory responses were significantly lower in $\mathrm{Tg} 8$ than in $\mathrm{C} 3 \mathrm{H}$ mice $(p<$ 0.05 ) for both minute ventilation and $V_{\mathrm{T}}$ (Fig. 5C). However, when four $\mathrm{Tg} 8$ mice were submitted to severe hypoxia $\left(7 \% \mathrm{O}_{2}\right.$; data not shown), both minute ventilation $\left(\Delta V_{\mathrm{E}}=+60 \pm 30 \%\right)$ and $V_{\mathrm{T}}\left(\Delta V_{\mathrm{T}}=+32 \pm 9 \%\right)$ increased, whereas the respiratory frequency was either increased $(n=3)$ or decreased $(n=1)$. Therefore, both strains were sensitive to hypoxia, but the threshold for the regulatory responses in the $\mathrm{Tg} 8$ mice was higher than in the $\mathrm{C} 3 \mathrm{H}$ mice.

\section{Respiratory responses to lung inflation}

The inspiratory command elaborated within the respiratory centers is modulated by vagal afferents: lung inflation activates vagal pulmonary stretch receptors (PSRs) that in turn delay the inspiratory command. This inhibitory loop, which is known as the Hering-Breuer reflex (Hering and Breuer, 1868; Widdicombe, 1964), is weak but present in $\mathrm{C} 3 \mathrm{H}$ mice (Burnet and Hilaire, 1999). TOs of $1 \mathrm{sec}$ that block the air flow at the very end of inspiration to maintain lung inflation increased the expiration durations in six $\mathrm{C} 3 \mathrm{H}$ mice $\left(T_{\mathrm{E}}=55 \pm 14 \%\right.$ of the preceding expirations; $p<0.01$ ) and therefore delayed the on-switches of the next inspirations (Fig. 6A, left), whereas in eight Tg8 mice, no significant variations in the expiration durations were seen $\left(T_{\mathrm{E}}=\right.$ $-2 \pm 3 \%$; NS), and thus there were no delayed on-switches of the next inspirations (Fig. $6 A$, right).

The small $V_{\mathrm{T}}$ in Tg8 mice, however, might have induced a bias in the respiratory responses to end-inspiratory TOs. Therefore, TOs of 2 sec duration were performed during expiration, and during these TOs, the lungs were overinflated with a given volume of air, the value of which was increased for each successive TO, to determine the volume-threshold necessary to delay the next inspiratory on-switch, up to the end of the whole $2 \mathrm{sec}$ occlusion period (Fig. 6B). In five $\mathrm{C} 3 \mathrm{H}$ mice the volumethreshold was $\sim 200 \mu \mathrm{l}(200 \pm 18 \mu \mathrm{l}$, median \pm semi-interquartile range) because the next inspiration occurred either just before (Fig. 6B, left, top traces) or just after (Fig. 6B, left, bottom traces) the end of the TOs. Identical experiments performed on six Tg8 mice (Fig. 6B, right) revealed that the volume-threshold was significantly larger $(316 \pm 25 \mu \mathrm{l}$, median \pm semi-interquartile range; $p<0.001$ ). Thus the Hering-Breuer reflex is present in both $\mathrm{C} 3 \mathrm{H}$ and $\mathrm{Tg} 8$ mice, but the lung volume-threshold is significantly larger in $\mathrm{Tg} 8$ than in $\mathrm{C} 3 \mathrm{H}$ mice.

To check whether the respiratory medullary networks in the two strains had different sensitivity to pulmonary vagal afferent inputs, the central end of the severed vagal nerve was electrically stimulated in four $\mathrm{C} 3 \mathrm{H}$ mice (Fig. 6C, left) and four $\mathrm{Tg} 8$ mice (Fig. 6C, right). Trains of electrical stimuli (100 Hz, 2 sec) were applied at various intensities. Below $10 \mu \mathrm{A}$, the respiratory discharges were not affected, whereas above 15-20 $\mu \mathrm{A}$, the inspira- 

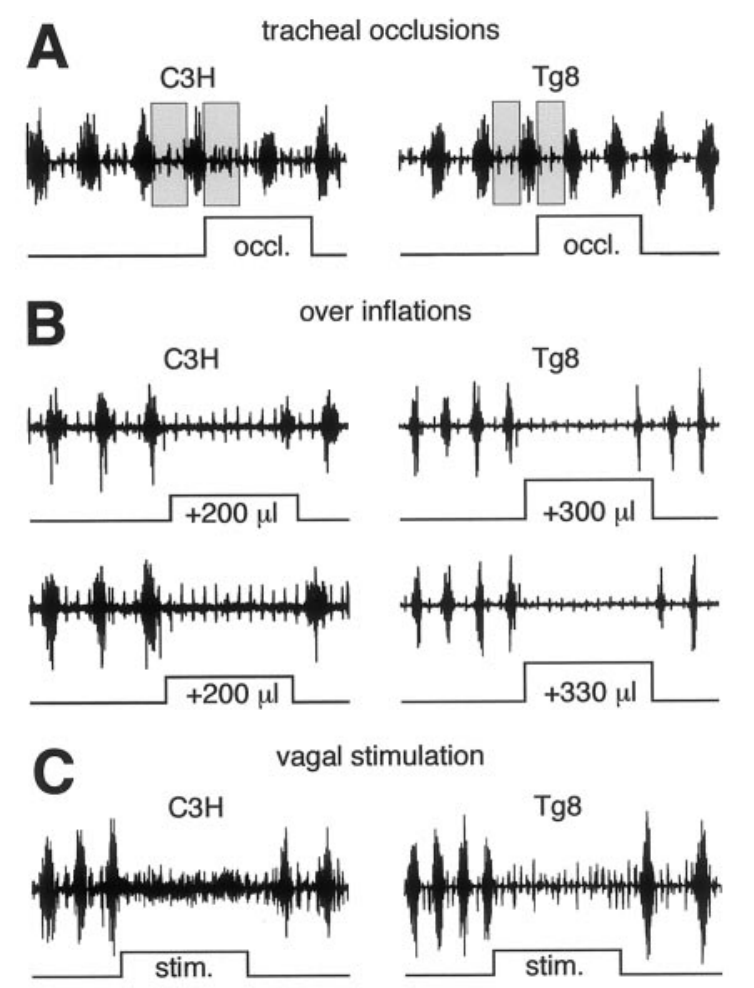

Figure 6. $\mathrm{Tg} 8$ mice are less sensitive to lung inflation than $\mathrm{C} 3 \mathrm{H}$ mice. $A$, Recordings from the Dia global EMGs in a $\mathrm{C} 3 \mathrm{H}$ mouse (left panel) and a Tg8 mouse (right panel) during $1 \mathrm{sec}$ tracheal occlusions (occl.) performed at the very end of the inspiration. The first gray bar indicates the duration of the expiration preceding the tracheal occlusion and is displayed with the next expiration to indicate the delay of the inspiratory on-switch produced by the tracheal occlusion. $B$, During expiration, the lungs are overinflated by injecting a known volume of air (in microliters) that is increased until the inspiratory on-switch is delayed up to the end of the $2 \mathrm{sec}$ occlusion. Recordings from the Dia global EMGs in a $\mathrm{C} 3 \mathrm{H}$ mouse (left panel) and a Tg8 mouse (right panel) during these $2 \mathrm{sec}$ occlusions show that the volume-thresholds to delay the inspiratory onswitches are higher in $\mathrm{Tg} 8$ than in $\mathrm{C} 3 \mathrm{H}$ mice. $C$, Electrical stimulation of the pulmonary vagal afferents at the central end of the severed vagus nerve for $2 \mathrm{sec}($ stim., $100 \mathrm{~Hz}$ ) elicits a similar inhibition of the Dia global EMGs in a $\mathrm{C} 3 \mathrm{H}$ mouse and a $\mathrm{Tg} 8$ mouse.

tory bursts were totally inhibited in both strains. Therefore, the sensitivity of the respiratory medullary networks to electrically activated vagal inputs was in the same range in both strains.

\section{Effect of modifying the 5-HT level by PCPA in adult Tg8 mice}

To determine whether the respiratory abnormalities of the adult Tg8 mice were caused by the high level of 5-HT still present, Tg8 mice were treated with PCPA, a 5-HT synthesis inhibitor, to decrease 5-HT levels. Plethysmographic measurements were performed on nine Tg8 mice before and after PCPA treatment. The treatment lengthened the mean value of $T_{\mathrm{I}}$ by $35 \pm 27 \mathrm{msec}$ and increased the mean value of $V_{\mathrm{T}}$ by $22 \pm 19 \mu \mathrm{l}$. Paired comparison revealed that these increases were not statistically different. Therefore, lowering endogenous 5-HT levels in Tg8 mice did not significantly modify their breathing pattern.

The 5-HT level can be responsible, however, for the weak respiratory responses of $\mathrm{Tg} 8$ mice to both hypoxia and vagal afferent inputs. First, PCPA treatment in $12 \mathrm{Tg} 8$ mice restored the respiratory responses to mild hypoxia $\left(10 \% \mathrm{O}_{2}\right)$. Hypoxia that did not affect the breathing pattern of the Tg8 control group (Fig.
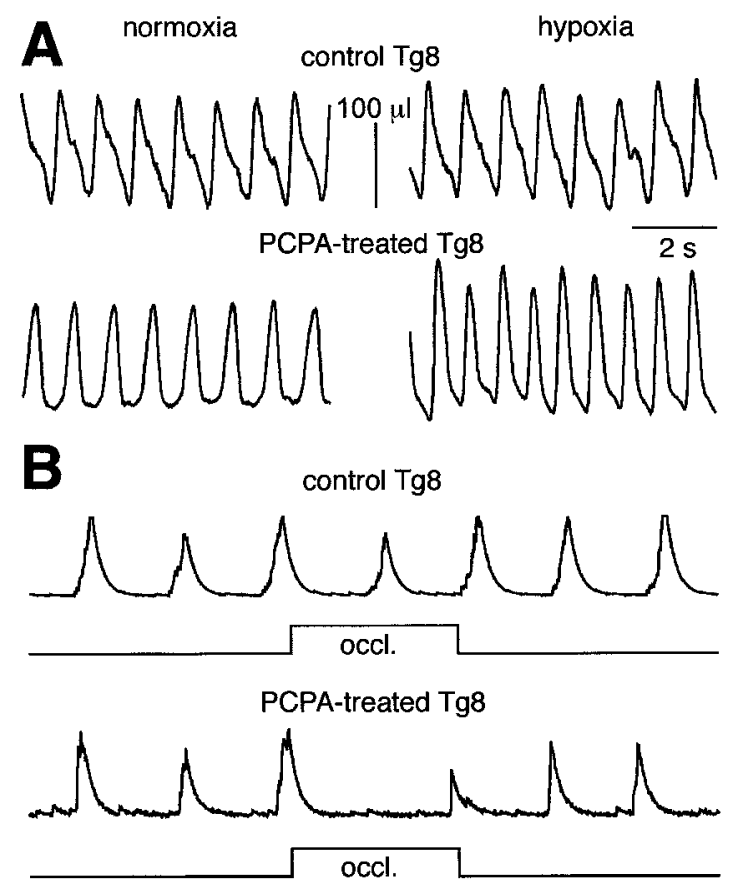

Figure 7. In Tg8 mice, PCPA treatments restore hypoxic and lung inflation responses. $A$, Plethysmographic measurements of respiratory activity during normoxia (left panels) and hypoxia (right panels) in a control Tg8 mouse (top traces) and a PCPA-treated Tg8 mouse (bottom traces). Hypoxia $\left(10 \% \mathrm{O}_{2}\right)$ does not significantly modify the breathing pattern in the control Tg8 mouse but increases both the frequency and tidal volume in the PCPA-treated mouse. $B$, Integrated discharges of the Dia global EMG are recorded from a control Tg8 mouse (top traces) and a PCPA-treated Tg8 mouse (bottom traces) during $2 \mathrm{sec}$ tracheal occlusions (occl.) performed at the end of inspiration. Occlusions have no effect in the control $\operatorname{Tg} 8$ mouse but delay the inspiratory on-switch in the PCPA-treated Tg8 mouse.

$7 A$, top traces $)$ significantly increased $(p<0.05)$ the minute ventilation $\left(\Delta V_{\mathrm{E}}=46 \pm 11 \%\right), V_{\mathrm{T}}\left(\Delta V_{\mathrm{T}}=38 \pm 21 \%\right)$, and respiratory frequency $\left(\Delta f_{\mathrm{R}}=+14 \pm 8 \%\right)$ in the treated animals (Fig. 7A, bottom traces). Second, PCPA treatment in four Tg8 mice restored the respiratory responses to pulmonary inflation. End-inspiratory TOs that did not affect respiration in control Tg8 mice (Fig. $7 B$, top traces) were able to lengthen the expiratory durations and delay the on-switches of the next inspirations in the treated mice (Fig. 7B, bottom traces).

\section{DISCUSSION}

In adult monoamine oxidase A-deficient Tg8 mice (Cases et al., 1995), breathing patterns, inspiratory neuron activities, and respiratory regulations are different from those of the normal $\mathrm{C} 3 \mathrm{H}$ strain. $\operatorname{Tg} 8$ mice present smaller tidal volumes, shorter inspirations, higher Dia and MIN activity, and lower IntC activity. In addition, Tg8 IntCMns have a number of abnormally large cell bodies. Finally, Tg8 mice are less sensitive to hypoxia and lung inflation than $\mathrm{C} 3 \mathrm{H}$ mice. The possible origins of these differences are discussed below.

\section{Abnormal respiratory regulations in adult Tg8 mice}

In mammals, respiration is regulated mainly by sensory inputs from the lungs and by chemosensory inputs from the carotid bodies.

First, vagal PSRs activated during lung inflation (Sant'Ambrogio, 1982; Davies et al., 1996) excite medullary interneurons mono- 


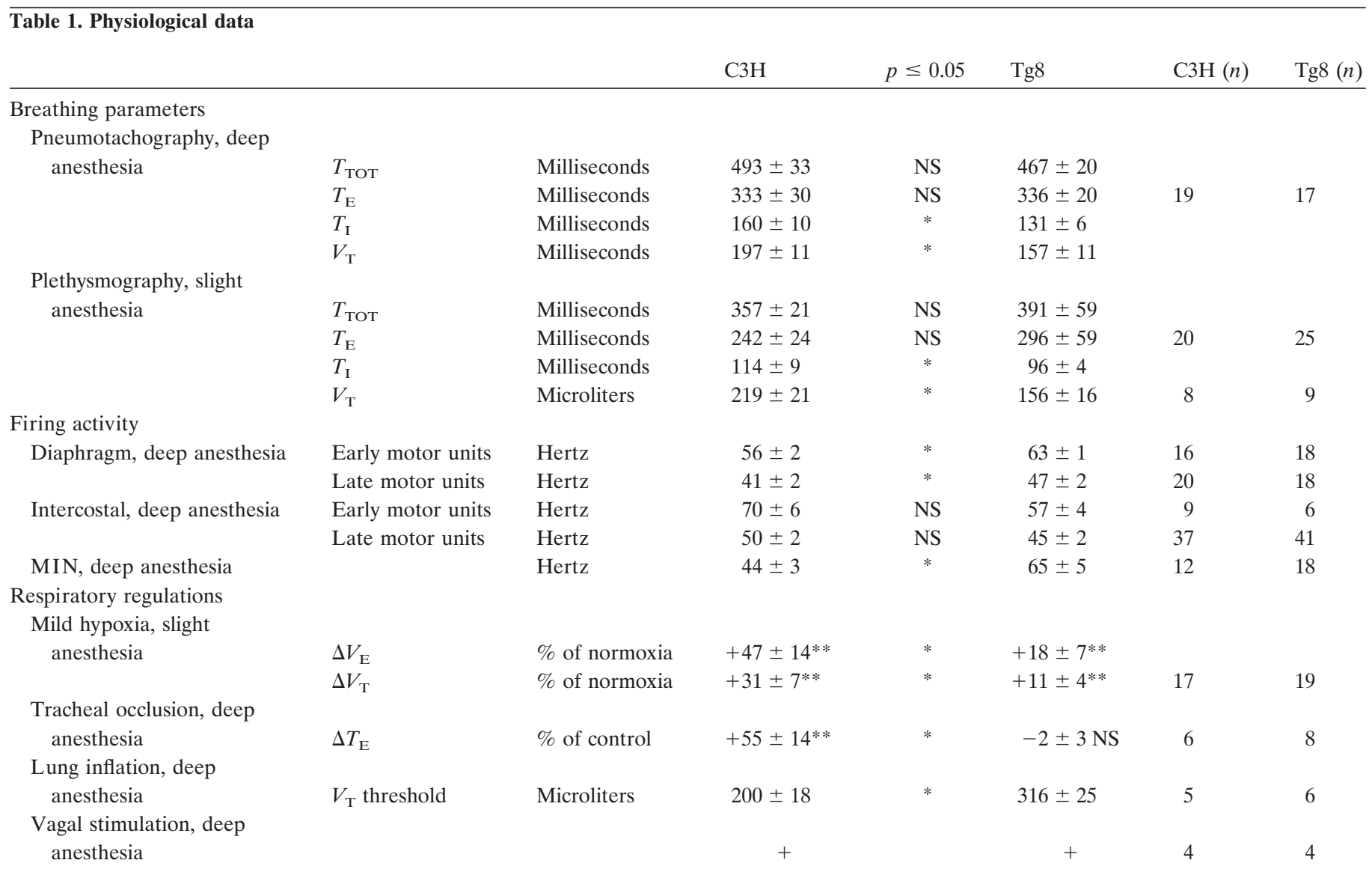

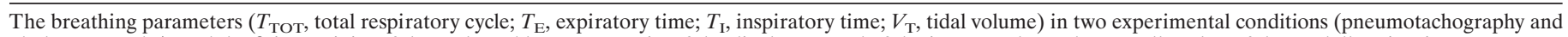

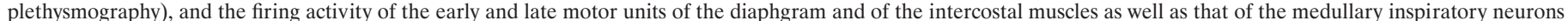

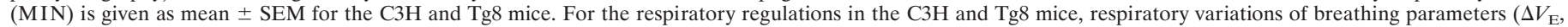

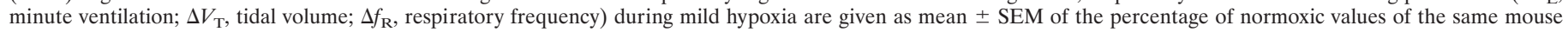

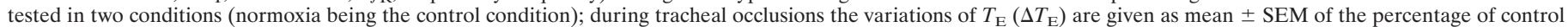

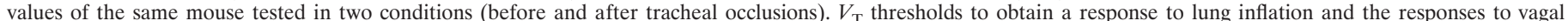

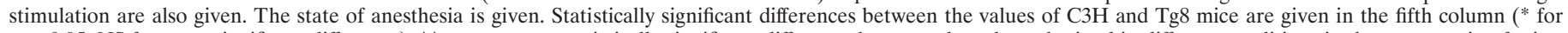

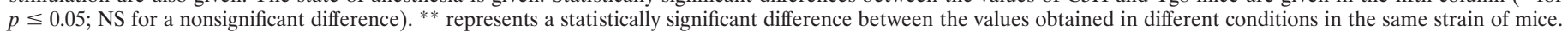
In the last two columns, $n$ gives the number of neurons or animals studied.

synaptically (Bonham and McCrimmon, 1990; Bonham et al., 1993). These, in turn, inhibit inspiration, delaying the inspiratory on-switches and lengthening $T_{\mathrm{E}}$ (Widdicombe, 1964; Hayashi et al., 1996; Burnet and Hilaire, 1999). This is observed in $\mathrm{C} 3 \mathrm{H}$ mice, but lung inflation during expiration in $\mathrm{Tg} 8$ mice does not lengthen $T_{\mathrm{E}}$. This response difference in Tg8 mice could have arisen either from weak sensitivity of PSRs to lung inflation or from weak sensitivity of the Tg8 medullary respiratory centers to PSR inputs. This study shows that (1) PSRs respond to lung inflation in both strains, although the necessary lung volume to induce a lengthening of $T_{\mathrm{E}}$ is larger in $\mathrm{Tg} 8$ mice, and (2) electrical stimulation of the vagus nerve, which contains the PSR afferents, similarly lengthens $T_{\mathrm{E}}$ in both strains. Therefore the response differences between the two strains probably arise from a difference in PSR sensitivity to lung inflation (Sant'Ambrogio, 1982; Iscoe, 1992; Burnet and Hilaire, 1999). Because 5-HT affects PSR sensitivity (Levitt and Mitzner, 1989; Matsumoto and Shimizu, 1989), the high 5-HT level in Tg8 mice may alter PSR sensitivity as shown by the restoration of normal respiratory responses to lung inflation in PCPA-treated Tg8 mice.

Second, hypoxia stimulates ventilation via the activation of the chemosensors of the carotid bodies (Hlastala and Berger, 1996), the afferents of which likely use substance $\mathrm{P}$ as neurotransmitter to signal hypoxia to their brainstem targets (Gillis et al., 1980; Kalia et al., 1984; Lindefors et al., 1986; Holtman, 1988). Under mild hypoxia, minute ventilation increases more in $\mathrm{C} 3 \mathrm{H}$ than in Tg8 mice. The weakness of the Tg8 response may arise from low sensitivity of the respiratory centers to substance P (Ptak and Hilaire, 1999) or from interactions between substance $P$ and 5-HT (Chahl, 1983; Holtman, 1988; Jacquin et al., 1989). Recovery of normal sensitivity to hypoxia in PCPA-treated Tg8 mice further argues for the implication of their high level of 5-HT.

\section{Abnormal breathing pattern in adult Tg8 mice}

Although the $\operatorname{Tg} 8$ respiratory centers do not elaborate a stable respiratory command at birth (Bou-Flores et al., 2000), they generate a stable respiratory activity in adults. However, after using different recording methods, our study reveals that $V_{\mathrm{T}}$ is smaller and $T_{\mathrm{I}}$ shorter in $\mathrm{Tg} 8$ mice. These abnormal $V_{\mathrm{T}}$ and $T_{\mathrm{I}}$ could reflect an abnormal sensitivity of $\mathrm{Tg} 8$ mice to anesthesia, but this is unlikely because the other breathing parameters (Table 1) are not affected and similar responses to anesthesia (induction time and duration) occur in the two strains. Therefore these abnormal breathing parameters probably arise from abnormal regulations or from abnormal elaboration of the central respiratory command. 
As for the former hypothesis, it is difficult to reach a conclusion because PSR and hypoxic afferent inputs have opposite effects (inhibiting vs facilitating inspiration, respectively), and an adaptation of the respiratory system to the weakness of the regulations may have occurred (Roux et al., 2000). In addition, the high 5-HT level in Tg8 mice may have induced cardiovascular alterations that may have indirectly affected breathing. However, the fact that PCPA treatments in Tg8 mice restore normal sensitivity to lung inflation and hypoxia without significantly affecting their $T_{\mathrm{I}}$ and $V_{\mathrm{T}}$ suggests that the weakness of these regulations does not play a crucial role in defining the breathing parameters.

As for the latter hypothesis, little information about the organization and activity of the respiratory central drivers is available in mice. Most of our knowledge has been obtained in adult cats (Monteau and Hilaire, 1991; Bianchi et al., 1995). Their PhrMns receive respiratory inputs from medullary drivers through both a monosynaptic pathway and a paucisynaptic one to which cervical interneurons belong. IntCMns receive their respiratory inputs through a paucisynaptic pathway with relay interneurons at cervical and thoracic levels of the spinal cord. In mice, the medullary drivers are still unknown, but the MINs that we recorded from belong to pathways that excite the PhrMns, as suggested (1) by our spike-triggered-averaging analyses, (2) by the medullary neurons labeled after the rabies virus injections in the Dia, and (3) by Fluoro-Ruby-stained cervical fibers after medullary injections in the MIN area. In addition, rabies virus injections in the IntC muscle label MINs at the same location. The recorded MINs in both strains seem to constitute a homogeneous group based on their medullary location and firing pattern.

Yet, the MIN firing rate differs in the two strains. In Tg8 mice, the low MIN activity before inspiration may delay the depolarization of the PhrMn membrane potentials up to their firing thresholds, therefore shortening $T_{\mathrm{I}}$; their higher firing rate during inspiration may contribute to the stronger discharges of the DiaMUs. Two hypotheses may be put forward to explain the different firing levels of the MINs in the two strains. First, the high level of 5-HT in adult Tg8 mice may increase their activity (Lalley et al., 1997); second, their morphology, excitability, and the medullary circuitry to PhMns and IntCMns may have been altered during maturation by the excess of 5-HT (Cases et al., 1996). Further work is needed to answer that question.

\section{Abnormal activity of Tg8 inspiratory motor units}

In Tg8 mice, the small $V_{\mathrm{T}}$ may arise directly from the short $T_{\mathrm{I}}$. Compared with $\mathrm{C} 3 \mathrm{H}$ mice, their Dia discharges are higher and yet do not produce larger $V_{\mathrm{T}}$. This suggests that the respiratory act is not fully efficient. Mechanically, the respiratory act is very complex because it involves the synergy of dozens of muscle pairs. Its efficiency depends on the coordination of the Dia with any muscle rigidifying the rib cage (Monteau and Hilaire, 1991), such as the IntC studied here. Indeed, in $\mathrm{Tg} 8$ mice, DiaMUs present a stronger activity than in $\mathrm{C} 3 \mathrm{H}$ mice, but surprisingly their IntCMU activity is weaker. Therefore, their strong Dia contractions are not counterbalanced by the IntC contractions: this may reduce the rib cage expansion during inspiration, hence reducing the $V_{\mathrm{T}}$.

The Mn firing activity depends on several factors such as membrane excitability, central driver and peripheral inputs, and modulatory processes. It is noteworthy that PhrMn cell bodies are similar in size in both strains, whereas IntCMns with large cell bodies are much more frequent in $\operatorname{Tg} 8$ mice, suggesting that PhrMn excitability is in the same range in both strains, whereas the IntCMn pool is less excitable in the Tg8 strain (Henneman et al., 1965a,b; Somjen et al., 1965). Therefore, the higher firing activity of the MINs during inspiration in Tg8 mice may produce the stronger Dia discharges, but it does not produce stronger IntC discharges in these mice. Besides, fewer cervical interneurons are found in $\mathrm{Tg} 8$ than in $\mathrm{C} 3 \mathrm{H}$ neonates (Bou-Flores et al., 2000). If their scarcity remains in adult Tg8 mice, this may contribute to further reduce the central driver inputs to the IntCMUs and therefore their activity. Finally, 5-HT affects the excitability of the respiratory Mns through different types of receptors (Lalley, 1986; Morin et al., 1991; Hilaire et al., 1997; Rekling at al., 2000; Talley and Bayliss, 2000) but depresses the transmission of both the central drivers (Di Pasquale et al., 1997) and the peripheral sensory inputs (Wallis et al., 1993) to the Mns. Because in addition to the central driver inputs the sensory ones are necessary for the firing activity of the IntCMUs but not for that of the DiaMUs (Monteau and Hilaire, 1991), high levels of 5-HT in Tg8 mice may further decrease the activity of the IntCMUs. However, in Tg8 mice treated with PCPA, the breathing pattern is not restored, which suggests that the firing activity of the respiratory MUs is not modified. Therefore, the high level of 5-HT still present in adults is not the crucial factor responsible for the weakness of the IntC activity, and these alterations probably arise from altered maturation of some elements of the respiratory network under prenatal and postnatal 5-HT high levels.

To conclude, there are differences in the breathing patterns and respiratory regulations of the two strains studied. The Tg8 mouse abnormalities seem to result both from abnormal maturation of the respiratory network attributable to drastic perinatal levels of 5-HT (Lajard et al., 1999; Bou-Flores et al., 2000) and from the high 5-HT level still present during adulthood (Cases et al., 1995). Indeed, because lowering the 5-HT level by PCPA treatment in adult $\operatorname{Tg} 8$ mice does not significantly affect $V_{\mathrm{T}}$ and $T_{\mathrm{I}}$, their small $V_{\mathrm{T}}$ and short $T_{\mathrm{I}}$ are probably caused by abnormal maturation, and the fact that PCPA treatment restores the normal respiratory responses to both hypoxia and lung inflation proves the implication of the high 5-HT level present in the adults. Hence, studies of monoamine oxidase A-deficient mice reveal that 5-HT metabolism disorders during the perinatal period induce alterations of respiratory network maturation (Bou-Flores et al., 2000) that are not transient and induce respiratory dysfunction during adulthood. Our work also shows that 5-HT metabolism disorders in adults impair respiratory regulatory processes. Thus, pharmacological treatments that interact with 5-HT metabolism should be used cautiously.

\section{REFERENCES}

Astic L, Saucier D, Coulon P, Lafay F, Flamand A (1993) The CVS strain of rabies virus as transneuronal tracer in the olfactory system of mice. Brain Res 619:146-156.

Bartlett D, Tenney S (1970) Control of breathing in experimental anemia. Respir Physiol 10:384-395.

Bianchi A, Denavit-Saubié M, Champagnat J (1995) Central control of breathing in mammals: neuronal circuitry, membrane properties, and neurotransmitters. Physiol Rev 75:1-45.

Bonham A, McCrimmon D (1990) Neurons in a discrete region of the nucleus tractus solitarius are required for the Breuer-Hering reflex in rat. J Physiol (Lond) 427:261-280.

Bonham A, Coles S, McCrimmon D (1993) Pulmonary stretch receptor afferents activate excitatory amino acid receptors in the nucleus tractus solitarii in rats. J Physiol (Lond) 464:725-745.

Bou-Flores C, Lajard A, Monteau R, Seif I, De Maeyer E, Lanoir J, Hilaire G (2000) Abnormal phrenic motoneuron activity and morphology in neonatal monoamine oxidase A-deficient transgenic mice: possible role of serotonin excess. J Neurosci 20:4646-4656.

Burnet H, Hilaire G (1999) Pulmonary stretch receptor discharges and 
vagal regulation of respiration differ between two mouse strains. J Physiol (Lond) 519:581-590.

Cases O, Seif I, Grimsby J, Gaspar P, Chen K, Pournin S, Müller U, Aguet M, Babinet C, Shih JC, De Maeyer E (1995) Aggressive behavior and altered amounts of brain serotonin and norepinephrine in mice lacking MAOA. Science 268:1763-1766.

Cases O, Vitalis T, Seif I, De Maeyer E, Sotelo C, Gaspar P (1996) Lack of barrels in the somatosensory cortex of monoamine oxidase A-deficient mice: role of a serotonin excess during the critical period. Neuron 16:297-307.

Chahl L (1983) Substance P mediates atropine-sensitive responses of guinea pig ileum to serotonin. Eur J Pharmacol 87:485-489.

Davies A, Pirie L, Eyre-Todd R (1996) Adaptation of pulmonary receptors in the spontaneously breathing anaesthetized rat. Eur Respir J 9:1637-1642.

Di Pasquale E, Lindsay A, Feldman J, Monteau R, Hilaire G (1997) Serotonergic inhibition of phrenic motoneuron activity: an in vitro study in neonatal rat. Neurosci Lett 230:29-32.

Erickson J, Conover J, Borday V, Champagnat J, Barbacid M, Yancopoulos G, Katz D (1996) Mice lacking brain-derived neurotrophic factor exhibit visceral sensory neuron losses distinct from mice lacking NT4 and display a severe developmental deficit in control of breathing. J Neurosci 16:5361-5371.

Gillis R, Helke C, Hamilton B, Norman N, Jacobowitz D (1980) Evidence that substance $P$ is a neurotransmitter of baro- and chemoreceptor afferents in the nucleus tractus solitarius. Brain Res 181:476-481.

Hayashi F, Coles S, McCrimmon D (1996) Respiratory neurons mediating the Breuer-Hering reflex prolongation of expiration in rat. J Neurosci 16:6526-6536.

Henneman E, Somjen G, Carpenter DO (1965a) Functional significance of cell size in spinal motoneurons. J Neurophysiol 28:560-580.

Henneman E, Somjen G, Carpenter DO (1965b) Excitability and inhibitability of motoneurons of different sizes. J Neurophysiol 28:599-620.

Hering E, Breuer J (1868) Die Selbststeuerung der Athmung durch den Nervus vagus. Sirzungsberichte der Akademie der Wissenschaften Wien 57:672-677.

Hilaire G, Duron B (1999) Maturation of the mammalian respiratory system. Physiol Rev 79:325-360.

Hilaire G, Monteau R, Dussardier M (1972) Modalités de recrutement des motoneurones phréniques. J Physiol (Paris) 64:457-478.

Hilaire G, Bou C, Monteau R (1997) Serotonergic modulation of central respiratory activity in the neonatal mouse: an in vitro study. Eur J Pharmacol 329:115-120.

Hlastala M, Berger A (1996) Physiology of respiration. New York: Oxford UP.

Holtman J (1988) Immunohistochemical localisation of serotonin and substance $\mathrm{P}$ containing fibers around respiratory muscle motoneurons in the nucleus ambiguus of the cat. Neuroscience 26:169-178.

Iscoe S (1992) Pulmonary stretch receptor discharge patterns in eupnea, hypercapnia, and hypoxia. J Appl Physiol 53:346-354.

Jacquin T, Denavit-Saubié M, Champagnat J (1989) Substance P and serotonin mutually reverse their excitatory effects in the rat nucleus tractus solitarius. Brain Res 502:214-222.

Jacquin T, Borday V, Sneider-Maunoury S, Topilko P, Ghilini G, Kato F, Charnay P, Champagnat J (1996) Reorganization of pontine rhythmogenic neuronal network in Krox-20 knock-out mice. Neuron 17:747-758.

Kalia M, Fuxe K, Hökflet T, Johansson O, Lang R, Ganten D, Cuello C, Terenius L (1984) Distribution of neuropeptide immunoreactive nerve terminals within the subnuclei of the tractus solitarius of the rat. J Comp Neurol 222:409-444.

Lajard A, Bou C, Monteau R, Hilaire G (1999) Serotonin levels are abnormally elevated in the foetus of MAOA-deficient transgenic mouse. Neurosci Lett 261:41-44.

Lalley P (1986) Serotonergic and non-serotonergic responses of phrenic motoneurons to raphe stimulation in the cat. J Physiol (Lond) 380:373-385.

Lalley P, Benacka R, Bischoff A, Richter D (1997) Nucleus raphe obscurus evokes 5-HT-1A receptor mediated modulation on respiratory neurons. Brain Res 747:156-159.

Levitt R, Mitzner W (1989) Autosomal recessive inheritance of airway hyperreactivity to 5-hydroxytryptamine. J Appl Physiol 67:1125-1132.

Lindefors N, Yamamoto Y, Pantaleo T, Lagercrantz H, Brodin E, Ungerstedt U (1986) In vivo release of substance P in the nucleus tractus solitarii increases during hypoxia. Neurosci Lett 69:94-97.

Matsumoto S, Shimizu T (1989) Effects of 5-hydroxytryptamine on rapidly adapting pulmonary stretch receptor activity in the rabbit. J Auton Nerv Syst 27:35-38.

Monteau R, Hilaire G (1991) Spinal respiratory motoneurons. Prog Neurobiol 37:83-144.

Morin D, Monteau R, Hilaire G (1991) Serotonin and cervical respiratory motoneurons: intracellular study in the newborn rat brainstemspinal cord preparation. Exp Brain Res 84:229-232.

Préhaud C, Coulon P, Lafay F, Thiers C, Flamand A (1988) Antigenic site II of the rabies virus glycoprotein: structure and role in viral virulence. J Virol 62:1-7.

Ptak K, Hilaire G (1999) Central respiratory effects of substance P in neonatal mice: an in vitro study. Neurosci Lett 266:189-192.

Raux H, Iseni F, Lafay F, Blondel D (1997) Mapping of monoclonal antibody epitopes of the rabies P protein. J Gen Virol 78:119-124.

Rekling JC, Funk GD, Bayliss DA, Dong XW, Feldman JL (2000) Synaptic control of motoneuronal excitability. Physiol Rev 80:767-852.

Roux JC, Peyronnet J, Pascual O, Dalmaz Y, Pequignot JM (2000) Ventilatory and central neurochemical reorganisation of $\mathrm{O}_{2}$ chemoreflex after carotid sinus nerve transection in rat. J Physiol (Lond) 522:493-501.

Sagot Y, Rossé T, Vejsada R, Perrelet D, Kato AC (1998) Differential effects of neurotrophic factors on motoneuron retrograde labeling in a murine model of motoneuron disease. J Neurosci 18:1132-1141.

Sant'Ambrogio G (1982) Information arising from the tracheobronchial tree of mammals. Physiol Rev 62:531-569.

Schmued L, Kyriakidis K, Heimer L (1990) In vivo anterograde and retrograde axonal transport of the fluorescent rhodamine-dextranamine, Fluoro-Ruby, within the CNS. Brain Res 526:127-134.

Siegel S, Castellan N (1988) Nonparametric statistics for the behavioral sciences. New York: McGraw-Hill.

Somjen G, Carpenter DO, Henneman E (1965) Responses of motoneurons of different sizes to graded stimulation of supraspinal centers of the brain. J Neurophysiol 28:958-965.

Talley EM, Bayliss DA (2000) Postnatal development of 5-HT(1A) receptor expression in rat somatic motoneurons. Dev Brain Res 122:1-10.

Tankersley C, Fitzgerald R Levitt R, Mitzner W, Ewart S, Kleeberger S (1997) Genetic control of differential baseline breathing pattern. J Appl Physiol 82:874-881.

Tankersley C, Rabold R, Mitzner W (1999) Differential lung mechanisms are genetically determined in inbred murine strains. J Appl Physiol 86:1764-1769

Ugolini G (1995) Specificity of rabies virus as a transneuronal tracer of motor networks: transfer from hypoglossal motoneurons to connected second-order and higher order central nervous system cell groups. J Comp Neurol 356:457-480.

Wallis DI, Wu J, Wang X (1993) Descending inhibition in the neonate rat spinal cord is mediated by 5-hydroxytryptamine. Neuropharmacology 32:73-83.

Watson AHD, Burrows M (1981) Input and output synapses on identified motoneurones of a locust revealed by intracellular injection of horseradish peroxidase. Cell Tissue Res 215:325-332.

Widdicombe J (1964) Respiratory reflexes. In: Handbook of Physiology, Vol 1 (Fenn WO, Rahnn H, eds), pp 585-630. Baltimore: Waverly Press.

Zar J (1984) Biostatistical analysis. Englewood Cliffs, NJ: Prentice-Hall. 